PALAVRAS. Revista de Epistemología, Metodología y Ética del Psicoanálisis ISSN: 2468-9831

www.revistas.unlp.edu.ar/palavras

palavras@outlook.com.ar

Argentina

\title{
RESEÑA DEL LIBRO "EL SUJETO SEGÚN LACAN". AUTOR: GUY LE GAUFEY. EDITADO POR EDICIONES LITERALES. BUENOS AIRES. 2010- 160 PÁGS.
}

DOI $10.24215 / 24689831 \mathrm{e} 025$

Juan Cruz Martínez Methol

Cómo citar este artículo:

Martínez Methol, J. C. (2018). Reseña del libro "El sujeto según Lacan”. Palavras. Revista de Epistemología, Metodología y Ética del Psicoanálisis, 4, 70-77. Recuperado de www.revistas.unlp.edu.ar/palavras 


\section{RESEÑA DEL LIBRO “EL SUJETO SEGÚN LACAN". AUTOR: GUY LE GAUFEY. EDITADO POR EDICIONES LITERALES. BUENOS AIRES. 2010- 160 PÁGS.}

\section{Juan Cruz Martínez Methol *}

En "El sujeto según Lacan”, Guy Le Gaufey emprende la tarea de despejar la cuestión del sujeto en Jacques Lacan a través de una investigación del movimiento de su enseñanza.

Tomando como punto de partida que el término "sujeto" se revela inexistente en la obra freudiana, es uno de los pivotes de la apuesta de Lacan desde el comienzo. Sin embargo, serán necesarios algunos seminarios para que en el giro de los años sesenta se lance a elaborar una acepción del término ajena a la órbita filosófica. A partir de mayo de 1959, hacia el final del seminario El deseo y su interpretación (Lacan, 1958-59/2015), la urgencia de una nueva definición del sujeto y del objeto en juego en la cura analitica se hace sentir y Lacan se lanza a ello a través de múltiples tanteos hasta llegar, más de dos años después, durante las primeras sesiones del seminario La identificación (1961-62), a una fórmula particularmente ajustada donde sujeto y significante se co-definen: "El significante representa al sujeto para otro significante". Las modificaciones y los agregados, constantes en los seminarios, no parecen haber impedido que la fórmula se mantuviera hasta el final.

Se trata entonces de una búsqueda textual que penetra el hallazgo en su estructura interna y al mismo tiempo lo sitúa en relación con una serie de constreñimientos formales que se imponen a Lacan, lo que permite captar sus decisiones teóricas en relación con su materia: el inconsciente freudiano y la cura analítica.

El comienzo de esa búsqueda en los meses de abril y mayo de 1959 se vale de un montaje preciso del sujeto en su relación con la demanda. Desde 1953 hasta 1959, en cambio, persiste la argumentación del sujeto como

\footnotetext{
* Facultad de Psicología de la Universidad Nacional de La Plata, Argentina. Mail: jcmartinezmethol@yahoo.com.ar
} 
instancia de verdad, es decir, con su capacidad de mentir en relación con otro sujeto en el marco de la intersubjetividad.

El autor afirma que un primer viraje se apoya en el grafo del deseo y en la presentación de una secuencia "dramática" durante la cual se decidirá la ubicación del sujeto en su lazo con el significante y con el objeto de la pulsión.

Tomado en los desfiladeros de la demanda, el "niño" se embarca con el Otro en una relación significante en la que el Otro solicitado puede responder o no, por lo cual la respuesta a la demanda se desdobla en valor de satisfacción y en prueba de amor. Ese mítico niño buscará encontrar en el Otro el significante que lo representaría como sujeto.

Ese sujeto tropieza así con el punto dramático del orden significante: por un lado, en esa sustracción del Otro, el sujeto se desvanece marcado por un fading característico y por otro lado, ante el desfallecimiento simbólico, se ven convocados los medios de lo imaginario en un mecanismo propio de la psicosis que Lacan concibe en su seminario sobre el tema (1955-56/2004).

Después de estas precisiones, puede ser develada una extraña "fatiga" del sujeto en relación con las tesis sobre el esfuerzo de Maine de Biran, que permite releer la tesis de Lacan sobre el estadio del espejo a la luz del nuevo estatuto del sujeto concebido como corte de la cadena significante.

Al concebir el fantasma, Lacan tiene un elemento del mismo temple que el esfuerzo biraniano: en él, el sujeto se hace objeto, sin cesar por ello de ser sujeto, y eso debido a que ambos pertenecen a un mismo estatuto de "corte". Debido a esa sustracción del Otro intimado a responder en verdad, ese sujeto (tan narrativizado en la presentación) no tiene otra salida que la de poner por delante ese valor imaginario que Lacan nombra desde hace ya algunos años "objeto petit $a$ ", letra acrónima que da cuenta de su origen especular.

Le Gaufey concluirá este punto que llama "la fabricación del sujeto en Lacan" indicando su estilo narrativo pero al mismo tiempo denunciando lo poco de génesis que presenta el asunto. La narración es la vía para cifrar una constante estructural. Desde ese ángulo, el fantasma constituye un rodeo que impide que bloqueemos al sujeto, ya sea en su valor simbólico, ya sea en su valor imaginario, porque uno no es nada sin el otro. Si se puede 
decir que el fantasma se impone como la formación psíquica más singular para un individuo, a la vez fruto y matriz de su historia, es necesario acordar que esa singularidad es ella misma compuesta.

El autor puntúa que las precisiones de Lacan chocan con la "exasperación" de la forma reflexiva: el sujeto se... hace algo, casi en el mismo momento en que vendría a... eclipsarse. La gramática en cuestión dará lugar a una interrogación del "juego de las voces" en su dimensión lingüística en relación con el posicionamiento del sujeto que de allí se infiere.

El seminario posterior, La ética del psicoanálisis (1959-60/2007), no trabaja directamente la cuestión del sujeto. Aunque la preocupación es constante, no es explícita, en tanto suponer al sujeto es hacerlo funcionar, darle su régimen normal, señala el autor. La única mención consistente se sitúa el 11 de mayo de 1960, a propósito de la memoria en el texto freudiano.

Con el sujeto fading, Lacan sabe que tiene una "fórmula nueva", sin embargo, manifiesta una oscilación en la definición del sujeto aún por venir, puesto que este sujeto todavía es activo, es él quien representa, no es todavía representado. Urge sacarlo de esa postura de agente para hacerlo el resultado de una operación al término de la cual un significante será perdido, faltará al menos uno, la cadena estará agujereada, etcétera.

En el seminario siguiente, La transferencia (1960-61/2009), se tratará para Lacan de un giro en lo que hasta allí podía pasar por su definición de un sujeto sólo frente a otro sujeto. El estudio del Banquete privilegia la atopía de Sócrates e introduce la disparidad subjetiva. Así queda el lugar despejado para dar una nueva base a ese sujeto, pero hay que esperar a las sesiones de abril de 1961 para que la cuestión se retome, en el momento de aportar precisiones sobre el cifrado del falo simbólico, que pondrá a trabajar los lazos entre el sujeto y el significante, en tanto el falo es elevado al lugar de significante faltante.

La operación del sujeto tendrá lugar al inicio del seminario La identificación, durante las sesiones de noviembre y diciembre de 1961. El título del seminario vuelve candente el tema del sujeto, ya que hablar de 
identificación es hablar... de él. El rodeo será un tratamiento del cogito cartesiano a través del miento de los lógicos.

En este lugar y por primera vez de modo explícito, Lacan no atribuye más a ese nuevo sujeto el saber si miente o no. Lo excluye de cualquier saber respecto de la verdad de lo que dice. Allí, en esa disyunción del sujeto y del saber, inventa la expresión, hoy exitosa, del "sujeto-supuesto-saber".

El divorcio entre sujeto y saber, este último localizado en el lugar del Otro en tanto que ese Otro -aquí la otra cara de la novedad- se encuentra desubjetivado. La conjunción de ese sujeto y ese saber produce ese monstruo, el "prejuicio más radical" que el análisis tiene que denunciar: el sujeto supuesto saber. Esa disyunción se vuelve entonces condición para poder articular de manera clara sujeto y significante: ese sujeto corte, escansión, intervalo, fading, evanescente, podrá no ser más que representado por un significante para otro significante, en tanto que se encuentra de-supuesto de todo saber, entendido como colección articulada de significantes. De ahora en más, no sabe nada, y eso por definición, no por accidente.

Ese sujeto que avanza sin reflexividad, incapaz de saber que sabe, ¿merece llamarse sujeto? Le Gaufey responde apelando al seminario El acto analítico (1967-68), sosteniendo la idea que ese sujeto presenta una problemática cercana a la temática del sujeto en Aristóteles. El sujeto llamado "aristotélico", sin reflexividad y sin ser, nada más y nada menos que la articulación entre significantes. Sólo la disyunción del sujeto y del saber podía permitir que ese sujeto sea reducido a no ser más que eso que es representado por un significante para otro.

El desarrollo termina con una pregunta que puede sorprender, y que polemiza con la tradición de la cuestión del sujeto en la filosofia, al menos desde Descartes hasta Hegel: ¿para qué mantener semejante término, si ese sujeto no es más el agente de nada, ni siquiera de su propio pensamiento, si no puede encontrar refugio en ninguna quiddité? ¿Qué es entonces lo que inventó Lacan al negar todo saber al sujeto y atándolo a la razón del significante?

Lacan fue tan lejos como podía en la aproximación del término "sujeto", pero el término "significante" seguía aún opaco. En las sesiones de 
noviembre y diciembre de 1961, se dedica a una distinción del signo y del significante que pueda tomar en cuenta al sujeto que promueve.

El significante, al revés del signo, no es lo que representa algo para alguien, es lo que representa precisamente al sujeto para otro significante. Lacan modificará la "fórmula del signo" de Peirce con la que cuenta hace años, sólo después de haber depurado ese nuevo sujeto de cualquier dimensión sustancial, retirándole todo saber y empobreciendo al significante hasta no ver en él más que el trazo único (einziger $Z u g$ ) que manifiesta todo elemento simbólico.

Dado que hay alli un sujeto nuevo, ¿qué hacer con el otro, con el sujeto mentiroso tomado en las redes de la intersubjetividad? ¿Se armonizan o se excluyen? Le Gaufey responde que tienen que coexistir porque el sujeto mentiroso es el sujeto del signo (engañador en principio, dado que se presenta para designar otra cosa que él) y que no es cuestión de prescindir ni del signo ni del sujeto que le está ligado. El sujeto mentiroso y el sujeto barrado: ¿el mismo o no el mismo? La interrogación implica el despliegue de una batería de términos asociados, sin los cuales el término sujeto no puede sostenerse, salvo en una constante homonimia.

En lo que sigue, el autor estudia en otros campos disciplinarios, el modo en que se ha pensado un sujeto sin identidad ni reflexividad.

Se trata en primer lugar del averroísmo latino, cuyas tesis fueron condenadas en 1270 y denunciadas por Tomás de Aquino (1994). Aquí como en otros lugares, es Alain de Libera $(2007,2008)$ la guía de Le Gaufey. La idea central del averroísmo que ataca Tomás resulta ser la de un pensamiento en exclusión interna con su sujeto. Hay cierta locura en esta concepción que ha sobrevivido a los siglos, y es la idea según la cual el polo subjetivo del pensamiento no es ningún hombre en particular. Al distinguir dos intelectos respetando el imperativo aristotélico: "nada puede estar a la vez y bajo la misma relación en potencia y acto", les fue necesario que el acto de pensar no se confundiera con la potencialidad de los pensamientos en el alma, lo que requería de ese clivaje del sujeto que Tomás rechaza con vigor dialéctico a fin de que el pecador pueda continuar siendo concebido individualmente culpable de sus pensamientos pecaminosos. 
El autor concluye que con el averroísmo se alcanza un concepto de sujeto ajeno a la identidad. Así, puede decirse que el sujeto lacaniano, sin identidad y sin reflexividad, se inscribe en una arqueología del sujeto.

El paso siguiente será el concepto de enunciado en el Foucault de La arqueologia del saber (1969/1983), donde se arriesga a pensar un sujeto fuera de las redes de la identidad. Foucault recusa, rechazando silenciosamente a Derrida (1963/1967), toda puesta en juego de un texto latente irreductible en la investigación de las formaciones discursivas, le deniega a los campos de saber su pretensión fundadora e individualizada, planteando el enunciado como un acontecimiento que ni la lengua ni el sentido pueden agotar por completo.

El autor se pregunta por el estatuto del sujeto a través de la función enunciativa. Si el sujeto es un lugar vacío -una función discursiva- y determinada de tal modo que no varía constantemente, se presenta de un modo bizarro y extraño, y si bien parece retomar su lugar clásico de condición de existencia del enunciado, lo hace con un matiz de indeterminación. La "función enunciativa" viene a despejar un lugar vacío devuelto al sujeto que requiere todo enunciado, volviendo a tal sujeto "posible" y no de entrada efectivo.

La reflexividad del sujeto rechazada en "La arqueología del saber", retorna en las producciones posteriores de Foucault bajo el modo de la reflexividad del "sí". Hemos pasado, de un sujeto clivado que se lee en la función enunciativa, de una distinción de lugares (sujeto posible indeterminado/sujeto actual determinado) a una tensión intima, un "sî" en devenir, investigado a través de una "historia del hombre del deseo y el placer".

Así como Foucault y los averroístas, cada uno a su manera, postulan un sujeto acéfalo y separado de lo humano, también Lacan, dirá el autor, ha inscripto a su sujeto en una función llamada "fálica" para asegurar su lazo con la sexualidad. Le Gaufey ha desarrollado este tema en detalle en su libro anterior: El notodo de Lacan (2007); aquí hará referencias puntuales. 
Finalmente, luego de situar, con Foucault y el averroísmo, que el sujeto no es de entrada nada ni nadie, pura posibilidad o lugar vacío, sin ninguna quiddité, Le Gaufey articulará el estatuto del sujeto lacaniano en relación a la noción de existencia y a la pulsión.

Lacan, al contrario de Saussure, minimiza el lazo significante/significado, al punto de reducir el significado a la monótona capa de "significancia" que sólo el corte significante viene a singularizar. El "entre dos" significantes del que hace el albergue del sujeto a partir de 1959, resuena en esa existencia que Foucault posicionaba en relación con la función enunciativa.

Sometiendo el concepto freudiano de pulsión a una nueva aproximación, Lacan llegó a diferenciar -en el seminario de Los cuatro conceptos (1964/2006)- la reflexividad especular y narcisística del amor y la exterioridad irreductible del objeto presente en el funcionamiento de la pulsión. Lacan intenta mostrar -concluye el autor- que lo que se presenta en el sujeto como alternancia actividad/pasividad, gana al ser concebido como un movimiento que cambia la posición del Otro, a saber, que ese Otro es producido como sujeto. Cuando el sujeto se hace objeto -de la mirada-, el que mira es el Otro. Por intermedio del juego pulsional el sujeto promueve con astucia a la dignidad de sujeto a ese Otro. La dificultad radica en el estatuto a dar al reflexivo "hacerse", gracias al cual el sujeto produce al Otro como sujeto sin por eso separarse él mismo de esa cualidad. Presentándose como objeto de la actividad del Otro, sin perder por eso su potencia de sujeto, dicho sujeto da muestras de una duplicidad que no es intencional y que necesita la reflexividad mínima del "se": él se hace objeto.

En su recorrido, Le Gaufey admite que la complejidad y las aparentes contradicciones, testimonian de una dinámica que hace de la enseñanza de Lacan una investigación del sujeto. 


\section{Referencias}

De Libera, A. (2007). Archéologie du sujet. Naissance du sujet. Paris: Vrin.

De Libera, A. (2008). Archéologie du sujet. La question de l'identité. Paris: Vrin.

Derrida (1963/1967). De la gramatología. Buenos Aires: Siglo XXI.

Foucault (1969/1983). La arqueología del saber. México: Siglo XXI.

Lacan, J. (1955-56/2004). Las psicosis. En El seminario (libro 3). Buenos Aires: Paidós.

Lacan, J. (1958-59/2015). El deseo y su interpretación. En El seminario (Libro 6). Buenos Aires: Paidós.

Lacan, J. (1959-60/2007). La ética del psicoanálisis. En El seminario (Libro 7). Buenos Aires: Paidós.

Lacan, J. (1960-61/2009). La transferencia. En El seminario (libro 8). Buenos Aires: Paidós.

Lacan, J. (1961-62). La identificación. En El seminario (Libro 9). Manuscrito inédito. Versión de la Escuela Freudiana de Buenos Aires.

Lacan, J. (1964/2006). Los cuatro conceptos fundamentales del psicoanálisis. En El seminario (libro 11). Buenos Aires: Paidós.

Lacan, J. (1967-68). El acto psicoanalitico. En El seminario (libro 15). Manuscrito inédito, Escuela Freudiana de Buenos Aires: Ciudad Autónoma de Buenos Aires: Argentina.

Le Gaufey, G. (2007). El no-todo de Lacan. Buenos Aires: El cuenco de plata. Tomás de Aquino (1994). Contre Averroès. Paris: Garnier-Flammarion. 